\author{
2상 유동 해석코드 CUPID를 이용한 \\ $\mathrm{CANDU}$ 원자로 감속재 열수력 예비해석 \\ 박상기 · 이재룡 ${ }^{*}$. 윤한영 ${ }^{*}$. 김형태* ${ }^{*}$ 정재준 ${ }^{* \dagger}$ \\ 부산대학교 기계공학부, "한국원자력연구원 \\ (2012년 9월 3일 접수, 2012년 12월 7일 수정, 2012년 12월 7일 채택)
}

\title{
Preliminary Analysis of the CANDU Moderator Thermal-Hydraulies using the CUPID Code
}

\author{
Sang Gi Park - Jae Ryong Lee ${ }^{*} \cdot$ Han Young Yoon ${ }^{*} \cdot$ Hyoung Tae Kim ${ }^{*}$ \\ - Jae Jun Jeong ${ }^{* \dagger}$ \\ School of Mechanical Engineering, Pusan National University, \\ "Korea Atomic Energy Research Institute(KAERI)
}

(Received 3 September 2012, Revised 7 December 2012, Accepted 7 December 2012)

$$
\text { 요 약 }
$$

본 연구에서는 기기 스케일 2상 유동(Two-phase flow) 해석 코드 CUPID를 사용하여 CANDU 원자 로의 칼란드리아 용기 내부 감속재의 열수력 거동을 분석하기 위한 사전연구를 수행하였다. 먼저, Stern 연구소에서 수행한 단상유동 실험 3종류를 이용하여 CUPID 코드를 검증하였다. 칼란드리아 관다발 영역 격자생성의 복잡성을 피하기 위하여 다공성 매질 모델을 해당 영역에 적용하였고, 다공성 매질 영역의 유동 저항은 실험에서 얻은 관계식을 이용하여 계산하도록 하였다. 계산결과, CUPID 코드는 칼란드리아 용기 내부의 강제 및 자연 대류의 혼합 유동 양식을 성공적으로 예측하였다. 다음으 로 2상 유동이 발생하는 경우를 해석하였다. 이들 계산을 통해 CUPD 코드의 CANDU 원자로 감속재 해석 능력을 보였다. 또한, 국부 과냉각 여유도를 예측하는데 사용할 수 있는 유입유량 대비 칼란드리 아 용기의 국부 최대 감속재 온도 그래프를 제시하였다.

주요어 : CANDU, 감속재, 온도 분포, 2상유동, CUPID

\begin{abstract}
A transient, three-dimensional, two-phase flow analysis code, CUPID, has been developed in KAERI In this work, we performed a preliminary analysis using the CUPID code to investigate the thermal-hydraulic behavior of the moderator in the Calandria vessel of a CANDU reactor. At first, we validated the CUPID code using the three experiments that were performed at Stern Laboratories Inc. To avoid the complexity to generate computational mesh around the Calandria tube bundles, a porous media approach was applied for the region. The pressure drop in the porous media zone was modeled by an empirical correlation. The results of the calculations showed that the CUPID code can predict the mixed flow pattern of forced and natural convection inside the Calandria vessel very well. Thereafter, the analysis was extended to a two-phase flow condition. Also, the local maximum temperature in the Calandria vessel was plotted as a function of the injection flow rate, which may be utilized to predict the local subcooling margin.
\end{abstract}

\footnotetext{
${ }^{\dagger}$ To whom corresponding should be addressed.

chool of Mechanical Engineering, Pusan National University,

30, Jangjeon-dong,

Geumjeong-gu, Busan, 609-735

Tel : 051-510-2455 E-mail : jjjeong@pusan.ac.kr
} 
Key words : CANDU, moderator, temperature distribution, two phase flow, CUPID

\section{1. 서 론}

중수형 원자로(CANDU)의 수평 원통형 탱크에는 사각 배열의 연료 채널이 관통하는데, 이 탱크를 칼 란드리아 용기(Calandria vessel)라고 하며, 내부에는 감속재(Moderator)라고 불리는 중수(Heavy water, $\mathrm{D}_{2} \mathrm{O}$ )가 채워져 있다 (Fig. 1 참조). 각 연료 채널은 중심이 같은 칼란드리아 관(Calandria tube)과 내부의 압력 관(Pressure tube)으로 구성되었고 두 개의 관 사이에는 이산화탄소가 절연 가스로 채워져 있다. 칼 란드리아 용기 내부의 감속재는 냉각시스템이 고장났 을 때 연료에서 발생하는 붕괴열(Decay heat)을 제거 하는 역할을 수행한다.

그런데 냉각재상실사고 등에서 압력 관이 변형되 어 칼란드리아 관과 접촉하면, 칼란드리아 관의 표면 온도가 아주 높아지면서 감속재 측에서 막 비등이 발 생할 수 있고, 이 경우 열전달이 저하되며 결과적으 로 핵연료 채널이 파손될 수 있다. 이와 관련된 실험 연구에서 감속재 과냉각도(Subcooling margin)가 충 분할 경우 막 비등은 발생하지 않는 것으로 나타났다. 따라서, 칼란드리아 용기 내부의 감속재 온도 분포를 정확히 예측하면 연료 채널의 건전성을 확인할 수 있 다 [1]. 그런데, 실제 원자로에서는 칼란드리아 용기 의 입구/출구 온도만이 측정하므로 내부의 온도를 예 측하려면 실험 및 게산 등의 등의 연구가 필요하다.

지금까지 칼란드리아 용기 내부의 국부 온도를 추 정하기 위해 수많은 실험과 수치 연구가 진행 되어왔 다. Stern 연구소의 Huget et al. [2,3]이 과도 상태와 정상상태 연구를 위해 실제 칼란드리아 용기의 $1 / 4$ 크기, 폭 $0.2 \mathrm{~m}$ 로 축소 설계한 실험 장치를 만들어 실험하였다. 또한 실험결과를 이용하여 MODTURC 과 MODTURC_CLAS 코드를 검증하였으며 다른 유 동 영역에 대한 실험과 수치해석 결과들을 비교하였 다. 캐나다의 Chalk River 연구소는 3 차원 감속재 측 정 장비를 구축하여 실험을 수행하였다 [4].

또한, CFD 코드를 사용하여 칼란드리아 용기의 열 수력을 예측하기 위한 많은 계산 노력도 있었다. 칼 란드리아 용기는 수많은 관 배열로 구성되어 있어 관 사이에 있는 모든 부수로에 대한 계산은 효과적이지
않아 일반적으로 다공성 매질 근사법을 채택하고 있 다. Hadaller et al. [5]은 칼란드리아 관다발 형상에 대한 압력 강하 모델을 구하고 MODTURC_CLAS 코드에 모델을 구현하였다. Yoon et al. [6, 7]은 $\mathrm{CFX}$ 코드에 다공질 매질의 압력강하 모델을 적용하 여 칼란드리아 용기의 3 차원 계산을 수행 하였으며 서로 다른 유동 영역에 대해서도 Stern $2 \mathrm{D}$ 실험 결과 와 수치결과를 비교하였다. 그런데, 거의 모든 실험 및 수치 연구는 2 상 유동보다 단상 유동의 국부 과냉 각에 초점이 맞추어져 있었다.

본 연구에서는 CUPID 코드를 이용하여 CANDU 원자로 감속재 열수력 예비해석을 수행하였다 [8]. CUPID 코드는 2 상 유동 계산을 위해 3 차원, 과도, 3 장 모델(Three-field model)과 다양한 물리 모델, 계 면 질량, 운동량 및 에너지 전달의 상관 관계식을 채 택하고 있다. 이 연구에서는 우선 Stern 연구소에서 수행된 단상 유동 실험 자료를 이용하여 CUPID 코 드를 검증하였다. 관다발 주변의 복잡한 격자 생성을 피하기 위해 다공성 매질을 채택 하였다. 이어서, 2상 유동 조건의 가상적인 실험을해석 하였으며, 추가적 으로, 유입유량 대비 칼란드리아 용기의 국부 최대 감속재 온도 그래프를 생성하여 국부 과냉각 여유를 예측하는데 사용할 수 있도록 하였다.

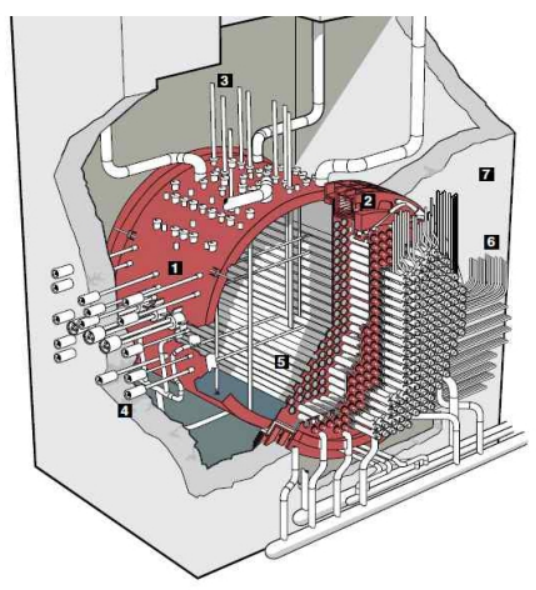

Fig. 1. Calandria vessel and fuel channels in a CANDU reactor 


\section{CUPID 코드 개요}

CUPID 코드에서는 2상 유동을 해석하기 위해 2 유체, 과도, 3장 모델을 채택하고 있다. 3 개의 장 (Field)은 연속 액체, 액적 및 증기를 나타낸다. 각 장 에 대한 질량, 에너지, 운동량 방정식으로 별도로 수 립하였으며, 각 장의 보본방정식은 계면 질량, 에너지 및 운동량 전달 모델로 서로 연결된다.

-k-장에 대한 연속방정식:

$\frac{\partial}{\partial t}\left(\alpha_{k} \rho_{k}\right)+\nabla \cdot\left(\alpha_{k} \rho_{k} \underline{u_{k}}\right)=\Omega_{k}$,

$\Omega_{g}=\Gamma_{v}+\Gamma_{\text {wall }}=-\Omega_{l}$.

- $\mathrm{k}$-장에 대한 운동량 방정식:

$$
\begin{aligned}
& \frac{\partial}{\partial t}\left(\alpha_{k} \rho_{k} \underline{u_{k}}\right)+\nabla \cdot\left(\alpha_{k} \rho_{k} \underline{u_{k}} \underline{u_{k}}\right)= \\
& -\alpha_{k} \nabla P+\nabla \cdot\left[\alpha_{k}\left(\tau_{k}+\tau^{T_{k}}\right)\right]+\alpha_{k} \rho_{k} g+\underline{M_{i k}} .
\end{aligned}
$$

여기서 $M_{i k}$ 는 계면 운동량 전달 항이다. 난류 유동 을 고려하기 위해서 표준 $k-\epsilon$ 난류 모델을 이용하 였다. 한편, 액체와 액적은 열적평형 상태에 있다고 가정하였다. 따라서 기체와 액체 장에 대한 에너지 방정식은 각각 다음과 같이 나타난다.

$$
\begin{aligned}
& \frac{\partial}{\partial t}\left(\alpha_{g} \rho_{g} e_{g}\right)+\nabla \cdot\left(\alpha_{g} \rho_{g} e_{g} \underline{u_{g}}\right)= \\
& -P \frac{\partial}{\partial t}\left(1-\alpha_{g}\right)+E_{i}^{D}-P \nabla \cdot\left(\alpha_{l} \underline{u_{l}}\right)+ \\
& Q_{i g}-Q_{g i}+q_{w g}, \\
& \frac{\partial}{\partial t}\left[\left(1-\alpha_{g}\right) \rho_{l} e_{l}\right]+\nabla \cdot\left[\left(\alpha_{l} \underline{u_{l}}+\alpha_{d} \underline{u_{d}}\right) \rho_{l} e_{l}\right] \\
& -P \frac{\partial}{\partial t}\left(1-\alpha_{g}\right)+E_{l}^{D}-P \nabla \cdot\left(\alpha_{l} \underline{u_{l}}\right) \\
& -P \nabla \cdot\left(\alpha_{d} \underline{u_{d}}\right)+Q_{i l}+Q_{g l}+q_{w l} .
\end{aligned}
$$

여기서 $E_{k}^{D}$ 는 전도, 난류 에너지 항과 점성 소멸 등 의 확산항(Diffusion terms)을 나타낸다. $Q_{i g}$ 와 $Q_{i l}$ 는 계면 에너지 전달 항이다. $Q_{g l}$ 은 비응축 기체-액체에 서 단위 체적당 열전달율이다.

상기 방정식 이외에 계면 견인력, 계면 열전달과 벽면 비등 모델, 상태 방정식 등이 Mathematical closure를 위해 필요하다. 위의 지배방정식을 풀기위 해 반내재적(Semi-implicit) 수치 기법을 개발 적용하
였다 [9-11].

액체-기체 계면에서 발생하는 열, 질량 및 운동량 전달은 액상과 기상의 계면 형태에 크게 의존하기 때 문에 이른바 유동양식(Flow regime) 모델을 이용하 여 계면의 상태를 결정한다. CUPID 코드에는 Tentner et al. [12]가 제안한 Inter-phase topology 개 념을 수정하여 채택하였다. 여기에서는 3 차원 2 상 유 동을 기포 유동, 액적 유동 및 날카로운 계면 (Sharp interface) 유동 등 3 개로 나누어 모델하고, 이들 유동 사이에는 천이유동(Transition flow) 영역을 두어 연 속적으로 연결되도록 하였다.

다공성 매질 영역(여기에서는 관다발 영역)의 압 력 강하를 모의하기 위해서는 적절한 모델이 필요하 다. 그런데, 관다발의 유동 저항은 비등방성을 갖기 때문에 유동 입사각을 정의하고, 축 방향과 수직방향 의 경험적 압력 강하 모델을 입사각의 함수로 상호 연계하여 비등방성 유동 저항을 표현할 수 있도록 하 였다 [8].

\section{3. 해석결과 및 논의}

본 절에서는 먼저 CUPID 코드의 다공성 매질 압 력강하 모델을 검증하였다. 그 다음, 축소 설계된 칼 란드리아 용기 실험설비에서 수행한 세 가지 경우의 단상 유동 실험 결과를 이용하여 CUPID 코드를 검 증하였다. 위의 세 가지 실험조건은 각각 등온 조건, 정상운전조건, 그리고 저유량 조건 (Low flow condition)이다. 마지막으로, 가상의 2상 유동 조건의 실험을 모의하고 논의한다.

\section{3-1 압력 강하 모델의 검증}

CUPID 코드의 다공질 매질 압력강하 모델을 검 증하기 위해 Stern Lab.에서 수행한 실험을 이용하였 다. 이 실험의 Test section은 $286 \mathrm{~mm} \times 200 \mathrm{~mm} \times$ $2,000 \mathrm{~mm}$ 의 사각채널로 In-line 및 Staggered array 형태의 관다발을 내장하고 있다 [5]. CUPID 계산에는 관다발 영역을 다공성 매질로 모델 하였고, 관다발 영역의 공극률과 투과율은 같다고 가정하였 다. 다공성 매질 마찰 압력강하 모델을 평가하기 위 해, 세 가지 유동조건의 실험을 두 가지 다른 격자로 모의하였으며, 그 결과 CUPID 코드의 최대 상대오차 는 $3.19 \%$ 로 나타났다 [8]. 


\section{3-2 공적분 검정}

Stern 연구소의 축소 설계된 칼란드리아 실험 장 치는 Fig. 2와 같이 구성되어 있다. $2 \mathrm{~m}$ 직경의 칼란 드리아 용기 내부에 직경 $33 \mathrm{~mm}$ 인 인코넬 관 440 개가 $71.5 \mathrm{~mm}$ 간격으로 삽입되어 있다. 관다발 속 전열기의 총 출력은 $100 \mathrm{~kW}$ 이다. 칼란드리아 용기 에 감속재를 주입하기 위해 설치한 입구노즐은 폭 $6 \mathrm{~mm}$ 이고 벽면에서 $50 \mathrm{~mm}$ 안쪽에 있으며 출구 노즐 은 폭 $15 \mathrm{~mm}$ 로 실험 장치 하단에 있다.

CUPID 코드는 비정렬 격자계를 기반으로 개발되 었다. 본 연구에서는 칼란드리아 용기를 모델하기 위 해 Fig. 2에 나타난 바와 같이 관다발영역은 다각 (Polyhedral) 격자로, 관다발 외부는 휘어진 정렬 격 자를 사용하였다. 다각 격자는 이웃 격자와 직교성이 높아 격자 면에서 압력 구배의 수치적 정확성을 보장 하고 상대적으로 적은 수의 격자에서도 정밀한 값을 얻을 수 있다.

본 연구에서는 10,000 개 격자를 적용하였고 특히, 정상상태 조건에서 격자 개수를 $4,000 ~ 10,000$ 개로 다르게 하여 격자 민감도를 확인하였다. 일반적으로 다공성 매질은 운동량을 감소시키는 역할을 하기 때 문에 운동량속 (Momentum flux)은 격자 분포에 상 대적으로 덜 민감하다. 그러나 외곽 유체 영역에 해 당하는 자유매질은 격자구성에 상대적으로 더 민감하 므로 자유매질에서 격자를 잘 만드는 것이 중요하다. 따라서 입구 노즐은 운동량속에 대한 불확실성을 최 소화하기 위해 격자들의 총 개수와 관계없이 단일 격 자 층으로 할당 하였다.

\section{3-2-1 등온 조건(Isothermal condition)}

Stern 연구소의 등온 조건 실험은 열 부하가 없고, 칼란드리아 용기의 냉각수 총 주입유량은 $2.4 \mathrm{~kg} / \mathrm{s}$ 이 다. 양쪽 입구 노즐로부터의 냉각수가 내부 원형 벽 면을 따라 상승하고, 최상단부에서 정체점(Stagnation pont)을 형성한 후 수직 중심선을 따라 하강한다. 수 직 중심선을 따라서 형성된 각각의 시계방향과 반시 계 방향 유동은 $\mathrm{y}$ 축 대칭을 이루고 있다.

Fig. 3(a)는 수직중심선에서의 수직 속도성분을 나타낸다. 다른 $\mathrm{CFD}$ 결과들과 마찬가지로, 하부 영 역에서의 속도 크기가 작게 예측되는 경향이 있다. 이는 다공성 매질의 체적 평균에 기인한다. Fig. 3(b) 는 입구 노즐로부터 ${ }^{\circ} 60$ 위치에서의 유체 접선 속도 를 반경방향에 따라 나타낸 것이다.
접선 속도는 격자 구조의 중심에서 원의 접선방향 속도 성분이다. CUPID 코드는 유체층의 다공성 매질 영역 부분에서 다른 코드의 수치 결과와 같이 실험 결과보다 높게 예측하고 있다. 그러나 벽면 근처부분 에서는 CUPID코드가 점착(No-Slip) 조건으로 인해 다른 코드 결과와 실험 데이터 보다 조금 낮게 예측 하고 있다.

\section{3-2-2 정상운전 조건}

실제 CANDU 원자로의 유동조건과 비슷한 정상 운전 조건(Normal operating condition)은 두 노즐에 서 주입되는 유량이 $2.4 \mathrm{~kg} / \mathrm{s}$ 이고, 감속재의 온도는 $55{ }^{\circ} \mathrm{C}$ 로 고정되어 있으며, 관다발의 총 열출력은 100 $\mathrm{kW}$ 이다. 본 계산에서는 수치적 안정성을 위해, 처음 $0 \sim 50$ 초 동안은 출력을 영(Zero)로 두었고, 50초 이 후 선형적으로 100 초 동안 전출력으로 증가하도록 설정하였다.

Fig. 4는 시간에 따른 유동분포의 천이과정을 나 타낸다. 유동은 Fig. 4(a)에서 보는 것과 같이 초기에 는 열 공급이 없으므로 등온 조건의 경우와 같다. 관 다발 영역, 즉, 다공성 매질 영역에 열을 공급하면 부 력이 서서히 생성되는데 부력이 증가함에 따라, 유동 은 $\mathrm{y}$-축 대칭이 무너지게 되고 Fig. 4(b)와 같이 비대

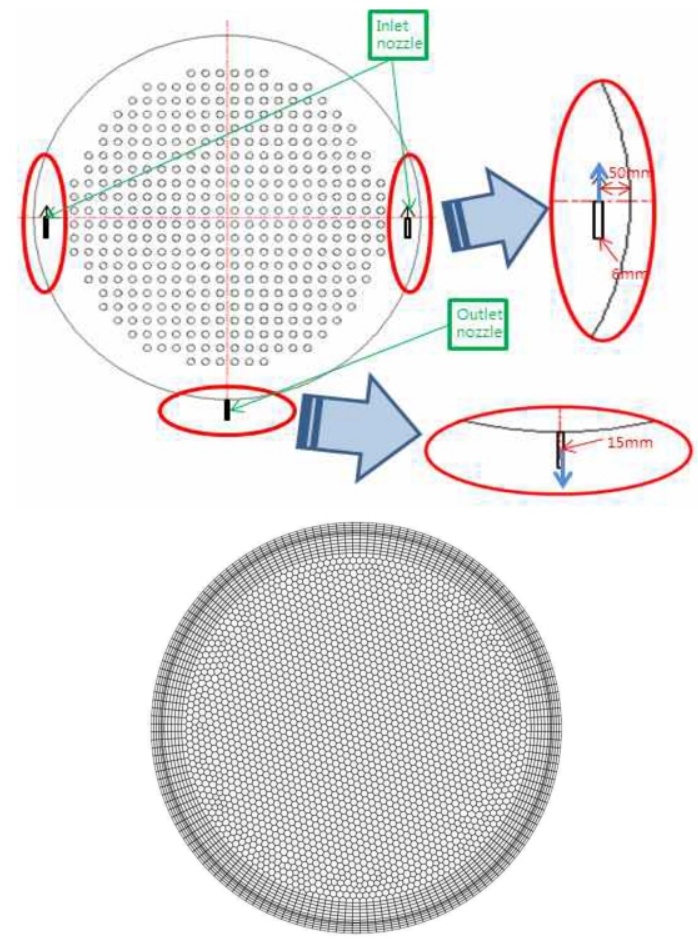

Fig. 2. Computational grid for the Calandria vessel 
칭 유동장 형태로 천이 된다. 유동장은 수력학적 불 안정성으로 인해 어느 방향으로나 기울어질 수 있다. 유동 대칭이 붕괴되면, 왼쪽 노즐 근처의 충돌 제트 는 Fig. 4(c)와 같이 지속적으로 발달하게 된다. 최종 적으로 Fig. 4(d)에 나타난 바와 같이 비대칭 유동 형 태로 유동 운동력과 부력 사이의 균형을 유지한다. 이러한 상태를 혼합 유동 형태라고 한다.

Fig. 5(a)는 y-축의 중심에서 격자 개수에 따른 유 체온도 분포를 나타내며, Fig. 5(b)는 $\mathrm{y}=0.57$ 에서 액 체 온도의 수평 분포를 나타낸다. 격자 민감도 결과 에서는 격자의 수가 작을수록 최고온도가 낮게 예측 되었다. 이것은 부력보다는 유체층의 운동량이 지배 적이라 발열 효과가 커지지 않기 때문이다. CUPID 코드의 계산 결과는 이전 연구자들의 실험 및 계산 결과와 비교적 잘 일치하는 것을 알 수 있다.

\section{3-2-3 저유량 조건}

본 계산에서는 칼란드리아 용기 입구유량을 정상 상태 조건의 $2.4 \mathrm{~kg} / \mathrm{s}$ 에서 $2.0 \mathrm{~kg} / \mathrm{s}$ 으로 줄이고, 열 출 력은 $100 \mathrm{~kW}$ 로 동일하게 유지하였다. Fig. 6은 저유

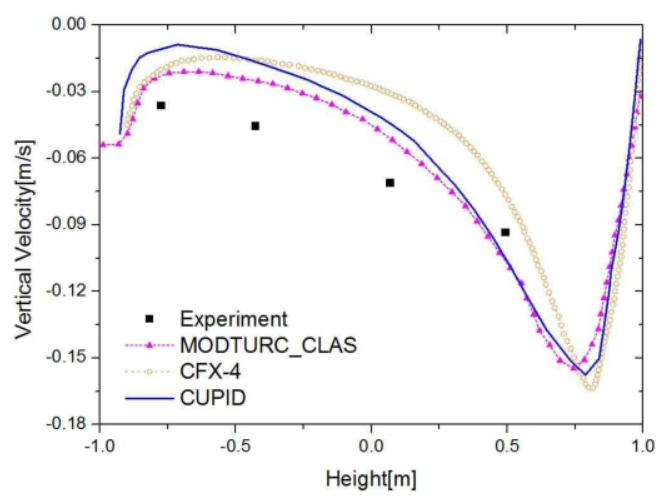

(a) Vertical velocity profile

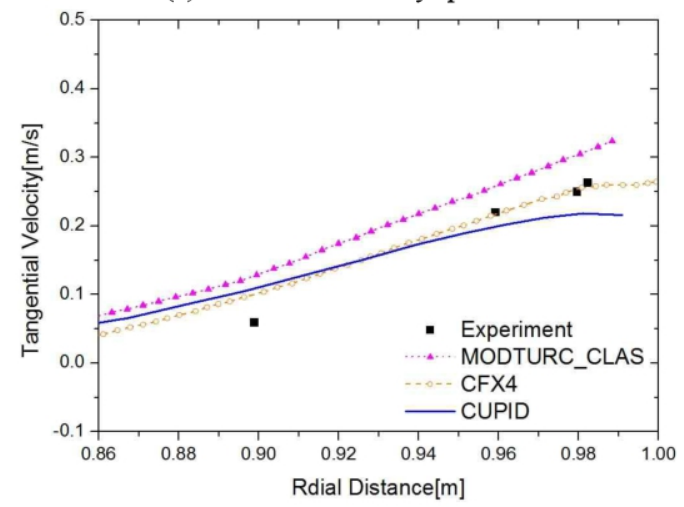

(b) Tangential velocity profile at 60

Fig. 3. Velocity profiles of the isothermal test
량의 액체 온도와 속도 벡터의 변화과정을 보여준다. 저유량이 공급되는 유동은 Fig. 6(a)과 Fig. 6(b)와 같 이 계산 초기에는 정상상태의 비대칭 유동장을 나타 내지만 내부 발열에 의한 부력이 상대적으로 크기 때 문에 Fig. 6(c)에서 보는 것처럼 충돌 제트는 주입 노 즐에서 격리되기 시작한다. Fig. 6(d)의 상부 영역은 부력에 의한 열성층화가 이루어져 자연대류 형태로 천이되었다. 정량적 비교에 사용할 수 있는 실험 데 이터가 없지만 혼합 유동에서 자연 대류 유동으로 전 환하는 형태를 CUPID 코드로 확인할 수 있었다. 자 연 대류에서 국부 최대온도 영역은 칼란드리아 용기 의 상부에 발생한다. 출구에서의 평균온도는 $67.05^{\circ} \mathrm{C}$ 이고 국부 최대 온도는 $78.72{ }^{\circ} \mathrm{C}$ 이다. 주입 유량 감소

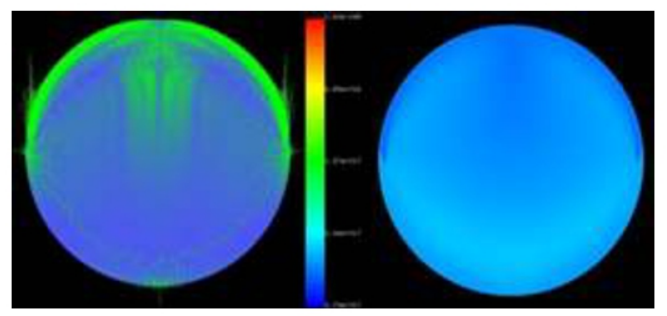

(a) $t=160 \mathrm{~s}$

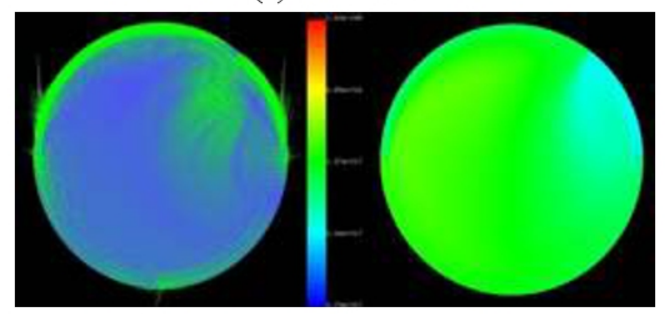

(b) $t=520 \mathrm{~s}$

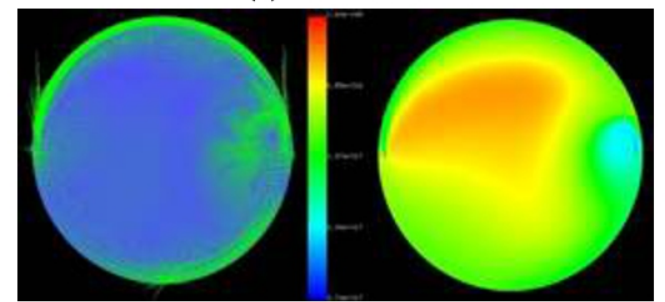

(c) $t=820 \mathrm{~s}$

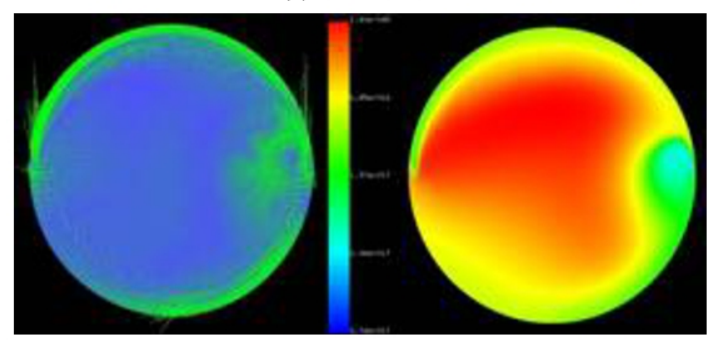

(d) $t=1500 \mathrm{~s}$

Fig. 4. Velocity and temperature contours for the normal operating condition 
로 국부 최대온도와 평균 출구 온도의 차이가 증가한 다. 그러므로 주입 유량이 더 감소하면 칼란드리아 용기의 상부영역에서 비등이 발생할 것으로 예상할 수 있다.

\section{3-3 2상 유동 조건}

선행연구를 통해, CUPID 코드는 유동 양식 변화 와 열성층화 과정 등을 예측할 수 있는 것으로 평가 되었다. 앞 절에서 계산한 실험조건에서 칼란드리아 용기 입구유량이 더욱 감소하면 부력의 영향이 커져 열성층화는 가속되고, 상부 영역의 과냉각은 줄어든 다. 결과적으로 열성층화가 지속되면 가열된 유체에 서 비등이 시작될 것이다.

가상적인 2상 유동조건을 도출하기 위해 칼란드 리아 용기 주입 유량을 정상상태의 $30 \%$ 에 해당하는 $0.7 \mathrm{~kg} / \mathrm{s}$ 로 하고, 출력은 정상상태 조건과 같게 하였 다. 이 경우, 정상상태에서 평균 출구온도는 포화 온 도보다 낮은 $89.80^{\circ} \mathrm{C}$ 로 평가된다. 그런데, 실제 계산 을 수행한 결과, 3-2-3절에서 유추한 바와 같이 열성

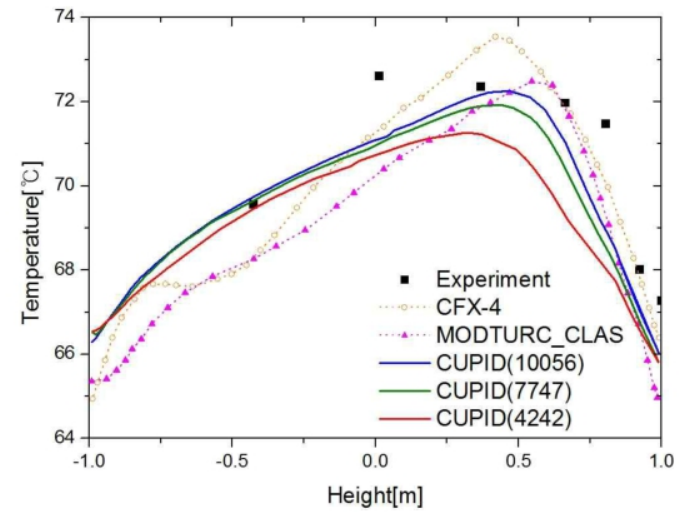

(a) Vertical profile at $\mathrm{x}=0$

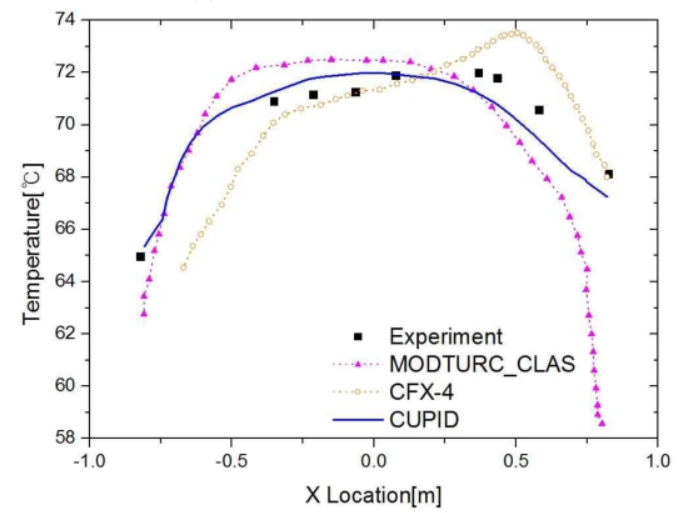

(b) Horizontal profile at $\mathrm{y}=0.57$

Fig. 5. Velocity profiles for the normal operating condition
층화에 이어 상부영역에서 비등이 발생하는 것으로 나타났다.

Fig. 7은 시간 경과에 따른 기포율 분포의 변화 를 보여준다. 비등은 최상부 영역부터 발생하며 과 열 수증기와 포화액체 사이의 경계면은 시간이 지나 면서 아래로 내려간다.

참고로, 세 가지의 입구유량 조건을 추가로 계산 하여, 주입유량 대비 평균 출구온도(에너지 평형에서 구한 값)와 CUPID 계산에서 얻은 국부 최대 온도 변 화를 Fig. 8에 나타내었다. 이 그림은 유입유량 대비 칼란드리아 용기의 국부 최대 감속재 온도를 예측하 는데 사용할 수 있을 것이다.

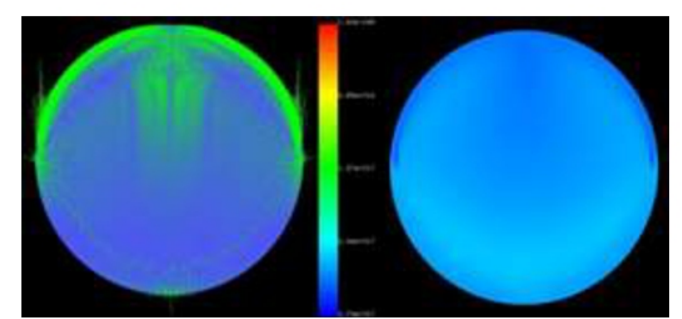

(a) $t=240 \mathrm{~s}$

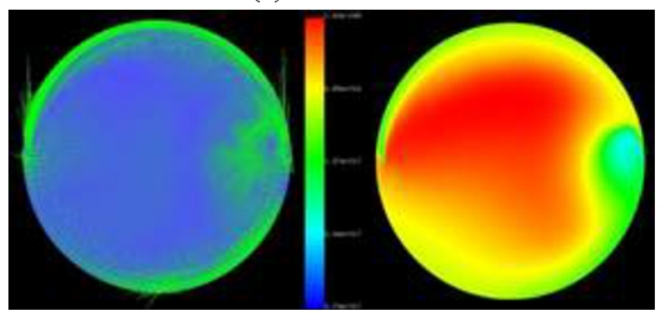

(b) $t=800 \mathrm{~s}$

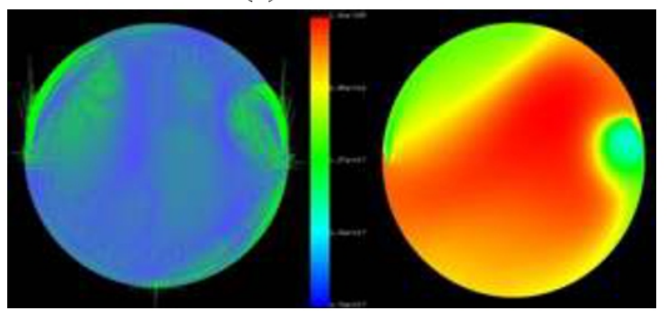

(c) $t=1100 \mathrm{~s}$

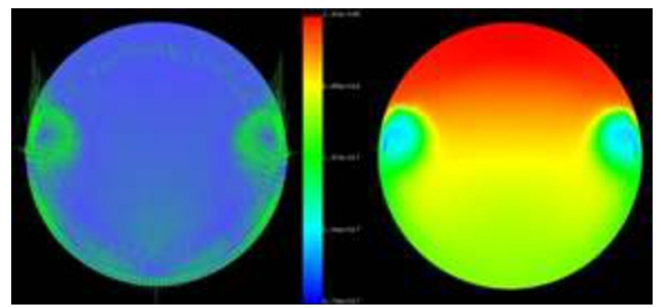

(d) $t=2000 \mathrm{~s}$

Fig. 6. Velocity and temperature contours for the low flow condition 


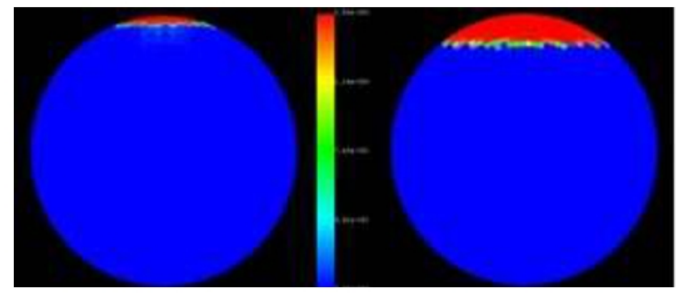

(a) $t=240 \mathrm{~s}$

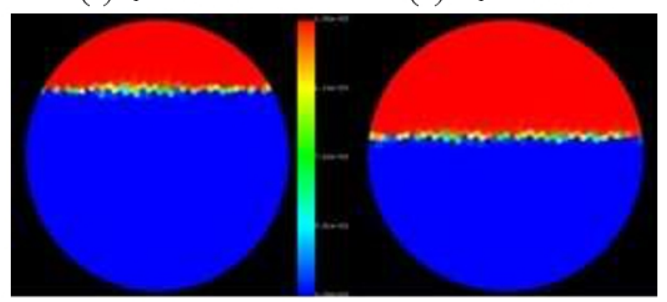

(c) $t=1100 \mathrm{~s}$

(d) $t=2000 \mathrm{~s}$

Fig. 7. Void distribution prediction for the two-phase flow condition

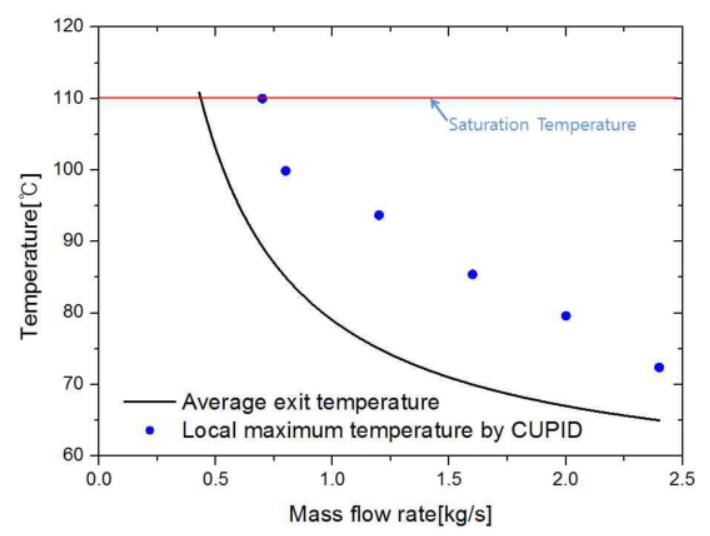

Fig. 8. Local maximum and average temperature at the exit versus the inlet flow rate

\section{4. 결 론}

본 연구에서는 기기 스케일 2상 유동 해석 코드 CUPID를 Stern 연구소에서 수행한 감속재 실험 결 과를 이용하여 검증하였다. 해석의 편의상, 칼란드리 아 관다발 영역은 다공성 매질 근사법으로 모델 하였 다. 그리고 운동량이 지배적인 유동, 혼합 유동, 부력 이 지배적인 유동의 세 가지 다른 실험을 선정하여 CUPID 코드로 계산 하였는데, CUPID 코드의 해석 결과는 기존의 실험 데이터 및 다른 코드의 해석결과 와 비교적 잘 일치하였다.

또한, 주입 유량을 저유량 조건보다 더 낮게 주입 시켜 계산을 수행하였다. 계산 결과, 내부유동은 부력
에 의한 영향이 지배적이었고, 용기의 상단 부분부터 2상 유동이 발생하는 것을 보여주었다. 추가적인 계 산을 통해 유입유량 대비 국부 최대 온도를 계산하여 과냉각여유도 예측에 사용할 수 있도록 하였다. 이와 같은 검증 계산 및 가상적인 2상 유동 계산을 통해 $\mathrm{CUPID}$ 코드를 CANDU 원자로 감속재의 단상 및 2 상 유동 해석에 적용할 수 있음을 보였다.

$$
\text { 후 기 }
$$

이 논문은 부산대학교 자유과제 학술연구비(2 년)에 의하여 연구되었음.

\section{참고문헌}

1. Fan, H.Z., Aboud, R., Neal P. and Nitheanandan, $\mathrm{T}$., "Enhancement of the Moderator Subcooling margin using Glass-peened Calandria tube in CANDU reactor s", Proceedings of 3 0th CNS Conference, Calgary, Alb erta,Canada, May 31-June 3, 2009.

2. Huget, R.G., Szymanski, J.K. and Midvidy, W.I., "Status of Physical and Numerical Modelling of CANDU Moderator Circulation," Proceedings of 10th Annual Conference of the Canadian Nuclear Society, Ottawa, 1989

3. Huget, R.G., Szymanski, J.K., Galpin, P.F. and Midvidy, W.I., MODTURC- CLAS: An Efficient Code for Analyses of Moderator Circulation in CANDU Reactors," Third International Conference on Simulation Methods in Nuclear Engineering, Montreal, Quebec, April 18-20, 1990.

4. Khartabil, H.F., Khartabil, W.W.R. Inch, Szymanski, J., Novog, D., Tavasoli, V. and Mackinnon, J., "Three-Dimensional Moderator Circulation Experimental Program for Validation of CFD Code MODTURC_CLAS," Proceedings 21-st Nuclear Simulation Symposium, Ottawa, Canada, Sep. 24-26, 2000 .

5. Hadaller, G.I. et al., "Frictional Pressure Drop for Staggered and In Line Tube Bank with Large Pitch to Diameter Ratio," Proceedings of 17th CNS Conference, Federiction, New Brunswick, Canada, June 9-12, 1996.

6. Yoon, C. et al., "Development and Validation of the 3-D Computational Fluid Dynamics Model for CANDU-6 Moderator Temperature Predictions", Nuclear Technology, vol.148, pp.259-267 (2004).

7. Yoon, C. et al., "Moderator Analysis of Wolsong Units $2 / 3 / 4$ for the $35 \%$ Reactor Inlet Header Break with a Loss of Emergency Core Cooling Injection", Journal of Nuclear Science and Technology, Vol. 43, No. 5, p. 505-513 (2006). 
8. Lee, J.R., Yoon, H.Y., Kim, H.T., Jeong, J.J., "Development Moderator Temperature Prediction by using Porous Media Approach", Proceedings of ICONE20, Anaheim, CA, USA, 2012.

9. Jeong, J.J., Yoon, H.Y., Park, I.K., Cho, H.K., Lee, H. D.: "Development and preliminary access of a three-dimensional thermal hydraulic code, CUPID", Nuclear Engineering AND Technology, Vol.42, No.3, pp.279-296 (2010).

10. Jeong, J.J, Yoon, H.Y., Park, I.K., Cho, H.K.: "The CUPID Code Development and Assessment Strategy", Nuclear Engineering AND Technology, Vol.42, No.6, pp.636-655 (2010).

11. Yoon, H.Y. et al.: "CUPID CODE MANUAL VOLUME I: Mathematical Models and Solution Methods", KAERI/TR-4403/2011, KAERI, 2011.

12. Tentner, A. et al.: "Computational Fluid Dynamics Modeling of Two-Phase Flow Topologies in a Boiling Water Reactor Fuel Assembly", Proceedings of ICONE16, Orlando, USA, 2008. 